Proc. of the International Conference on Advances in Bio-Informatics and Environmental Engineering - ICABEE 2016.

Copyright (C) Institute of Research Engineers and Doctors. All rights reserved.

ISBN: 978-1-63248-100-9 doi: 10.15224/ 978-1-63248-100-9-23

\title{
Effect of The Global Warming on Rangeland
}

\section{Yaşar ÖZYİĞíT}

Akdeniz University Korkuteli Vocational School Antalya/TÜRKIYE

\begin{abstract}
Global warming is called that increase in the average temperature of the earth's crust and the sea due to greenhouse gases such as carbon dioxide and it is one of the most serious challenges to world in nowadays. Many things cause global warming, for example carbon dioxide emissions from fossil fuel burning and gasoline burning for transportation, methane emissions from animals and deforestation.Climate changes have important effect on the life cycles of plants and animals. Many plants and animals need very specific climate conditions, such as temperature and rainfall, to live in their habitat. So plants and animals life can run a risk in case of any change in the climate of area. For example, many plants can no longer survive in their growing area or starting to grow and bloom earlier in the spring and survive longer into the fall. Also, some animals species have to migrate more suitable areas for their. Rangelands are natural or semi-natural areas of typically low productivity and are grazed by wild and domesticated animals. Climate change effects are very complex on rangelands. Because many plant species (grasses, grass-like plants, forbs or shrubs) are living together. In that review, effect of the climate changes on rangeland were investigated.
\end{abstract}

Key Word: Climate change, global warming, greenhouse effect, rangeland. 